\title{
A framework for identification and planning of environmental research needs to inform rehabilitation of Ranger uranium mine
}

MA Welch Department of Environment and Energy, Australia

RE Bartolo Department of Environment and Energy, Australia

AJ Harford Department of Environment and Energy, Australia

\begin{abstract}
Through the implementation of a framework to identify and prioritise environmental research needs, the knowledge required to successfully rehabilitate the Ranger uranium mine will be systematically obtained and applied to ensure rehabilitation objectives are achieved, and the people and the environment of Kakadu National Park are protected into the future. The framework initially involved a screening-level environmental risk assessment focused on rehabilitation and was undertaken in collaboration with the mine operator, subject matter experts, and stakeholders. Key identified risks included contamination of ground and surface water, soils and sediments; erosion of the constructed post-mining landform; failure to develop a functional and self-sustaining ecosystem; and radiation exposure to humans and the environment. A knowledge gap analysis was conducted against each of the high and critical risks identified in the risk assessment, which identified several key knowledge needs (KKNs). Research project/s required to address the KKNs were systematically identified and closely linked to the mine rehabilitation schedule, to ensure the information will be available when it is needed. A formal process, including review by stakeholders, has been developed to modify or close-out KKNs as research work is completed and the required knowledge is acquired.
\end{abstract}

Keywords: environmental risk assessment, rehabilitation planning, stakeholders, project management

\section{Introduction}

\subsection{The Alligator Rivers Region}

The Alligator Rivers Region covers an area of $28,000 \mathrm{~km}^{2}, 220 \mathrm{~km}$ east of Darwin in Australia's Northern Territory and includes the dual World Heritage listed Kakadu National Park and parts of western Arnhem Land (Figure 1). The area has a history of continuous Aboriginal occupation dating back over 50,000 years and contains some of the oldest known occupation sites in Australia. Aboriginal people continue to live and follow traditional cultural practices in the region today. Over the last 100 years, parts of the Alligator Rivers Region have been used for pastoral and mining activities including historical uranium mining in the 1950s and 1960s along the southern reaches of the South Alligator River in what is now Kakadu National Park.

The Alligator Rivers Region is dominated by an ancient sandstone escarpment, with extensive Ramsar-listed coastal wetlands to the north and large areas of eucalypt dominated tropical savanna. Rainfall in the Alligator Rivers Region is highly seasonal with approximately $1,500 \mathrm{~mm}$ of rain received between December and March. During the dry season, many of the waterways retreat to isolated billabongs and all but the largest rivers cease to flow. Over the wet season, the streams flood and the wetlands fill rapidly leading to a dramatic increase in ecosystem productivity. 


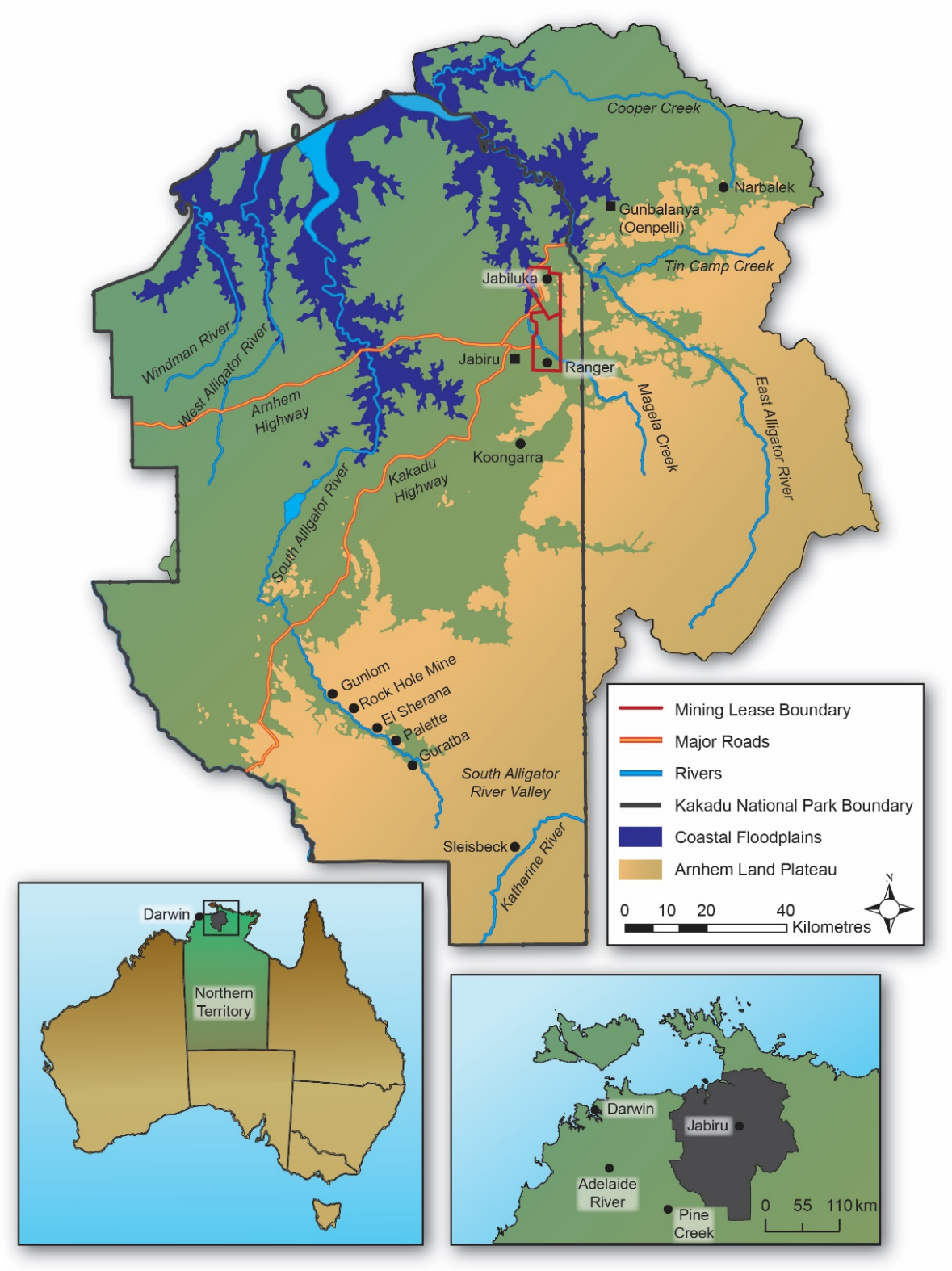

Figure 1 The Alligator Rivers Region and location of the Ranger uranium mine

Kakadu National Park is the largest national park in Australia and is included on both the World Heritage list and the Ramsar List of Wetlands of International Importance. Kakadu National Park supports a very high diversity of flora and fauna, with nearly 1,600 plant species, the highest diversity of freshwater fish in Australia (246 species), over one-third of all Australian bird species ( 271 species), 132 reptile species, and 27 species of frogs (Director of National Parks 2016). Kakadu's extensive wetlands provide an internationally significant habitat for a large number of endemic and migratory bird species.

Given the high cultural and ecological significance of the region, there is a strong expectation that the area is afforded the highest possible level of protection from the effects of uranium mining to ensure its conservation.

\subsection{Ranger uranium mine}

The Ranger uranium mine is located $250 \mathrm{~km}$ east of Darwin, Northern Territory. The Ranger Project Area is surrounded by Kakadu National Park (Figure 1). Operations commenced at Ranger in 1980 using conventional open cut mining methods and an acid leach extraction circuit and since 1980, has produced over 125,000 $t$ 
of uranium oxide. Mining activities at Ranger ceased in 2012 with the exhaustion of ore in Pit 3. Processing of ore from stockpiles must cease by 8 January 2021.

Approximately 850 ha ( $11 \%$ ) of the land surface within the Ranger project area has been affected by mining activities and will require rehabilitation.

\subsection{Rehabilitation regulatory requirements}

The rehabilitation objectives for Ranger are set out in the Environmental Requirements of the Commonwealth of Australia for the Operation of the Ranger Uranium Mine (Environmental Requirements) (Department of the Environment and Energy 1999) and include:

- Protection of the cultural and natural World Heritage values of Kakadu National Park from the possible effects of uranium mining.

- Rehabilitation of the Ranger project area to a sustainable ecosystem that is similar to, and could be incorporated into, the surrounding Kakadu National Park.

Although the Ranger Environmental Requirements reflect the science and understanding of rehabilitation at the time of compiling them, the way in which they are articulated is consistent with contemporary Australian ecological restoration standards (Standards Reference Group SERA 2017).

Under current regulatory requirements, rehabilitation works at Ranger must be completed in early 2026. The mine operator will not be released from its responsibility for closure of the site until the rehabilitation objectives in the Environmental Requirements and associated closure criteria have been met. Site closure is expected to take a considerable period beyond 2026, as ecosystems mature and the site stabilises. During this post-rehabilitation period, active site management will include remedial works where necessary (e.g. vegetation infill planting, erosion control, weed and fire management) and would be expected to decline over time.

\subsection{Role of the Supervising Scientist and research}

Due to the environmental sensitivity of the site and the contentious nature of uranium mining, the Supervising Scientist for the Alligators Rivers Region (Supervising Scientist) was established under the Environment Protection (Alligator Rivers Region) Act 1978 (EPARR Act) (Commonwealth of Australia 1978) for the purpose of protection and restoration of the environment in the region from the effects of uranium mining. The roles and functions of the Supervising Scientist under the EPARR Act include:

- Oversight of the regulatory process.

- Undertaking a program of environmental monitoring.

- Operation of an environmental research institute.

- Development of standards and procedures.

- Provision of advice to the minister in relation to the Ranger mine closure plan and achievement of the Environmental Requirements.

The regulatory oversight function of the Supervising Scientist includes both the operational and rehabilitation aspects of Ranger; to ensure regulation is effective and consistent with Commonwealth requirements. Activities include audit and inspection programs, incident investigations, assessment of management plans, reports and proposals, assessment of monitoring data, and participation in stakeholder consultation groups (Miller 2019).

The monitoring function involves a comprehensive and independent program to detect potential effects of uranium mining on people and the environment, including provision of data to inform the Supervising Scientist's other functions and to provide public assurance. The monitoring program is based on a 'multiple 
lines of evidence' approach, consistent with national guidance (Commonwealth of Australia 2018), including water quality, ecotoxicology, radiation exposure, aquatic and terrestrial ecology, and bioaccumulation.

The Environmental Research Institute of the Supervising Scientist (ERISS) undertakes targeted research to provide a rigorous scientific basis for the assessment of rehabilitation plans and the development of standards, practices, and procedures that ensure the highest level of environmental protection in the Alligator Rivers Region. Areas of expertise include aquatic ecology, environmental radioactivity, ecotoxicology, biochemistry, geomorphology, ecosystem restoration, and landscape ecology. Where required, additional expertise is sourced through strategic partnerships with other research organisations (e.g. universities) and industry expert consultants (e.g. engineering and hydrogeology). All research conducted by ERISS is publicly available.

The Alligator Rivers Region Technical Committee (ARRTC) is an independent scientific advisory panel that has been established to review research activities in the Alligator Rivers Region and the scientific basis for the environmental assessment and regulation of uranium mining operations. ARRTC is comprised of eminent environmental experts with a range of scientific qualifications and expertise including ecotoxicology, geomorphology, hydrology, hydrogeology, radiation protection and health physics, ecological risk assessment, mine site restoration, and ecology.

The primary functions of ARRTC are:

- To independently consider and review research into, and programs for the collection and assessment of information relating to, the effects of uranium mining operations on the environment in the Alligator Rivers Region, including Kakadu National Park.

- To make recommendations to the minister on the nature and extent of research necessary to protect and restore the environment in the region.

ARRTC reviews the quality and adequacy of the scientific research conducted by the Supervising Scientist, the mine operator, and other relevant stakeholders. This ensures that the environmental regulation of uranium mining in the Alligator Rivers Region continues to be guided by the best available science.

This paper describes the process that was undertaken to identify and plan the environmental research required to inform the successful closure of the Ranger uranium mine. This process is summarised in Figure 2.

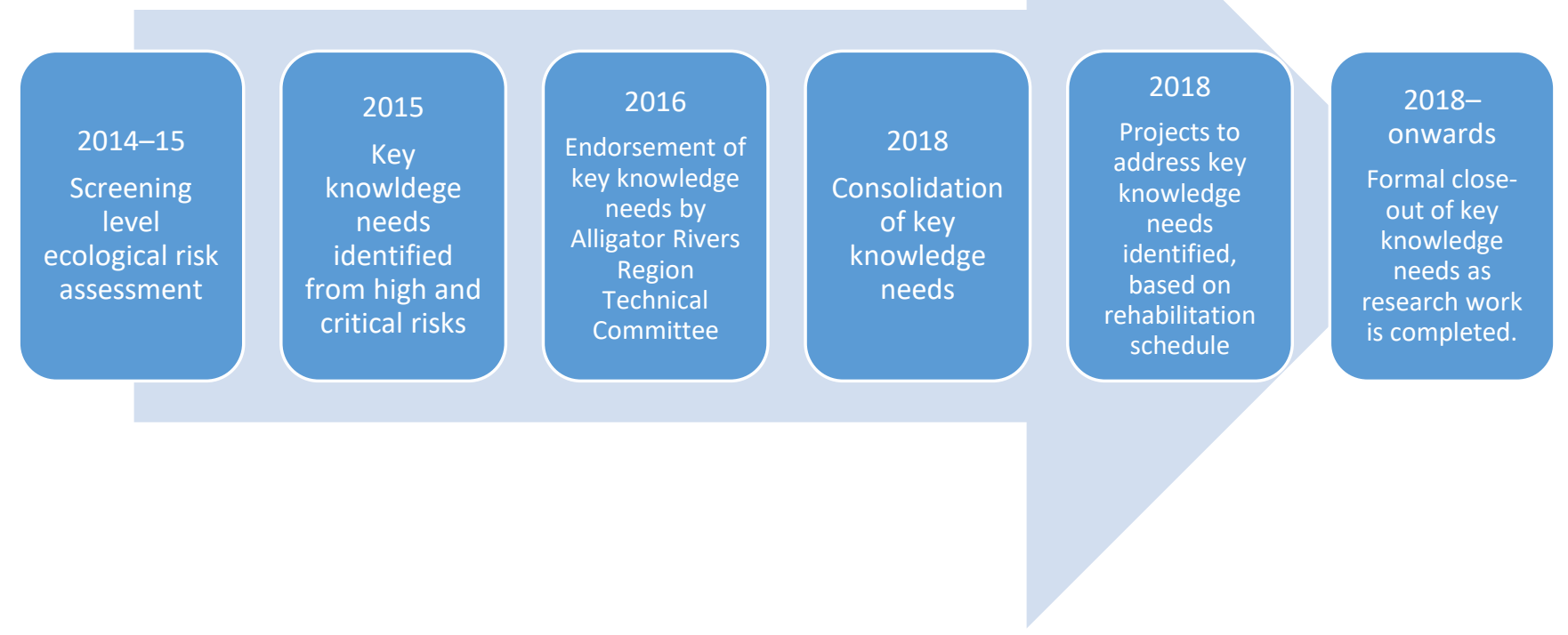

Figure 2 Process for development of the joint research program for Ranger rehabilitation 


\section{Framework for identification of environmental research needs}

\subsection{Environmental risk assessment}

Key potential risks following rehabilitation of Ranger include contamination of ground and surface water, soils and sediments; erosion of the constructed post-mining landform; failure to develop a functional and self-sustaining ecosystem; and radiation exposure to humans and the environment. A screening-level ecological risk assessment for Ranger rehabilitation was undertaken by the Supervising Scientist in collaboration with key stakeholders including the mine operator, experts from external organisations, representatives of local traditional owners and the ARRTC independent scientific review panel. Ecological risk assessments were based on the AS/NZS ISO 31000:2009 Risk management-principles and guidelines (Standards Australia/Standards New Zealand 2009) and the Guidelines for Ecological Risk Assessment (US Environmental Protection Agency 1998).

The risk assessment process involved the steps illustrated in Figure 3, which are discussed in more detail in Bartolo et al. (n.d.).

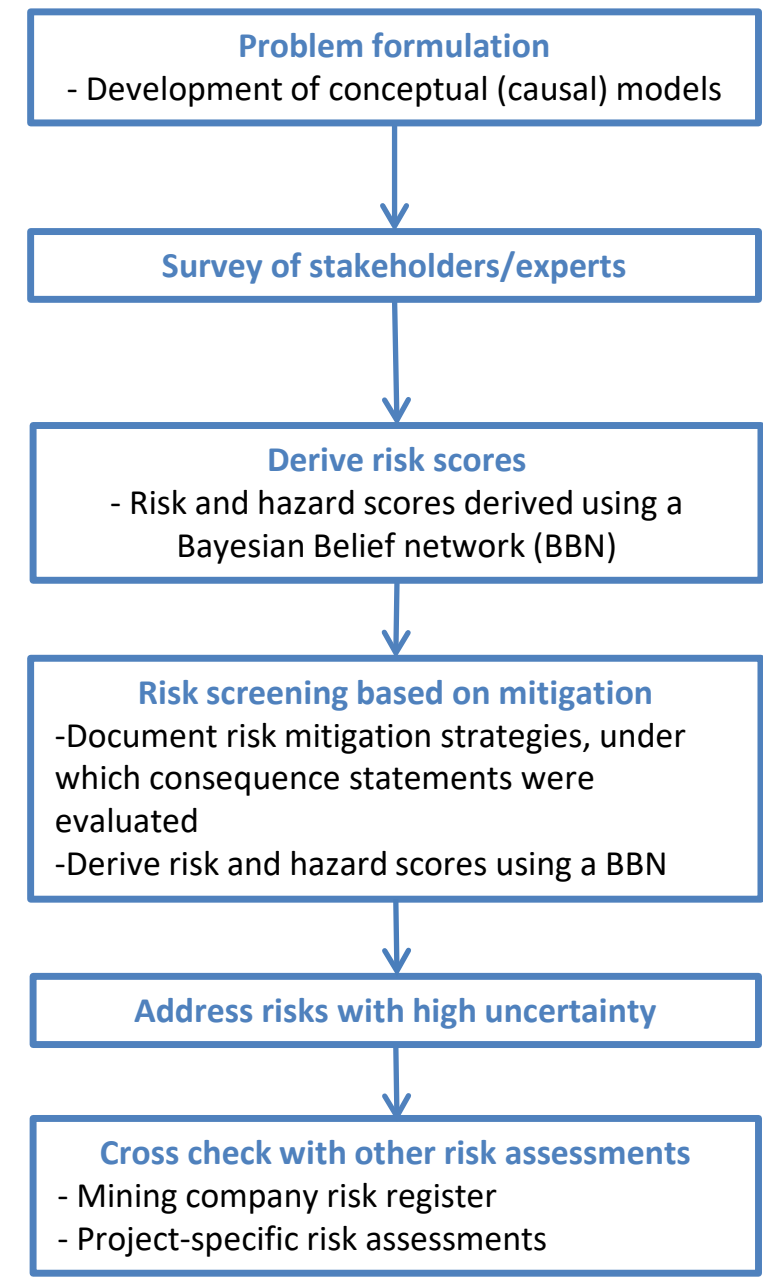

Figure 3 Overview of approach to screening-level ecological risk assessment for Ranger mine

\subsection{Identification of knowledge needs}

The high and critical risks identified in the ecological risk assessment (Bartolo et al. 2013) were evaluated further to identify the key risks and uncertainties that require additional knowledge. This process is outlined in Figure 4 and further details are provided in the following paragraphs. 


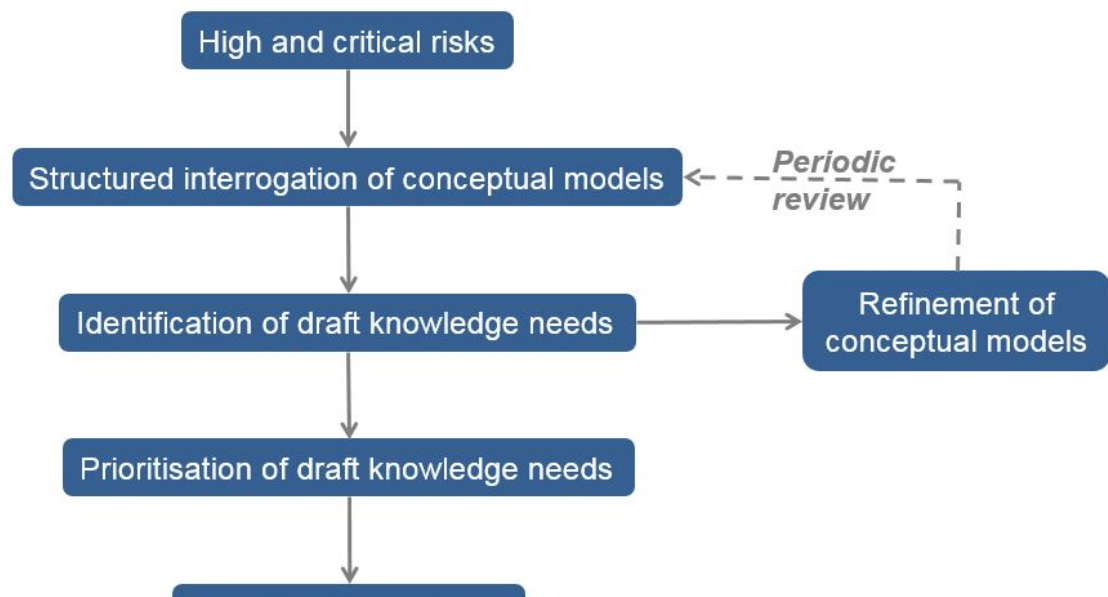

Key Knowledge Needs

Figure 4 Overview of process to identify key knowledge needs for Ranger mine

The issues underlying the high and critical risks were evaluated by interrogating the conceptual models that formed the original basis of the stressor-assessment endpoint combinations (e.g. contaminants - toxicity to wildlife) identified in the risk assessment (Figure 5). This step was also undertaken in consultation with experts in the key risk categories (i.e. contaminants, radiation, ecosystem restoration, and landform), including representatives of the mine operator, key stakeholders and scientific experts from ARRTC.

sources

and stressors measurement endpoint

assessment endpoint

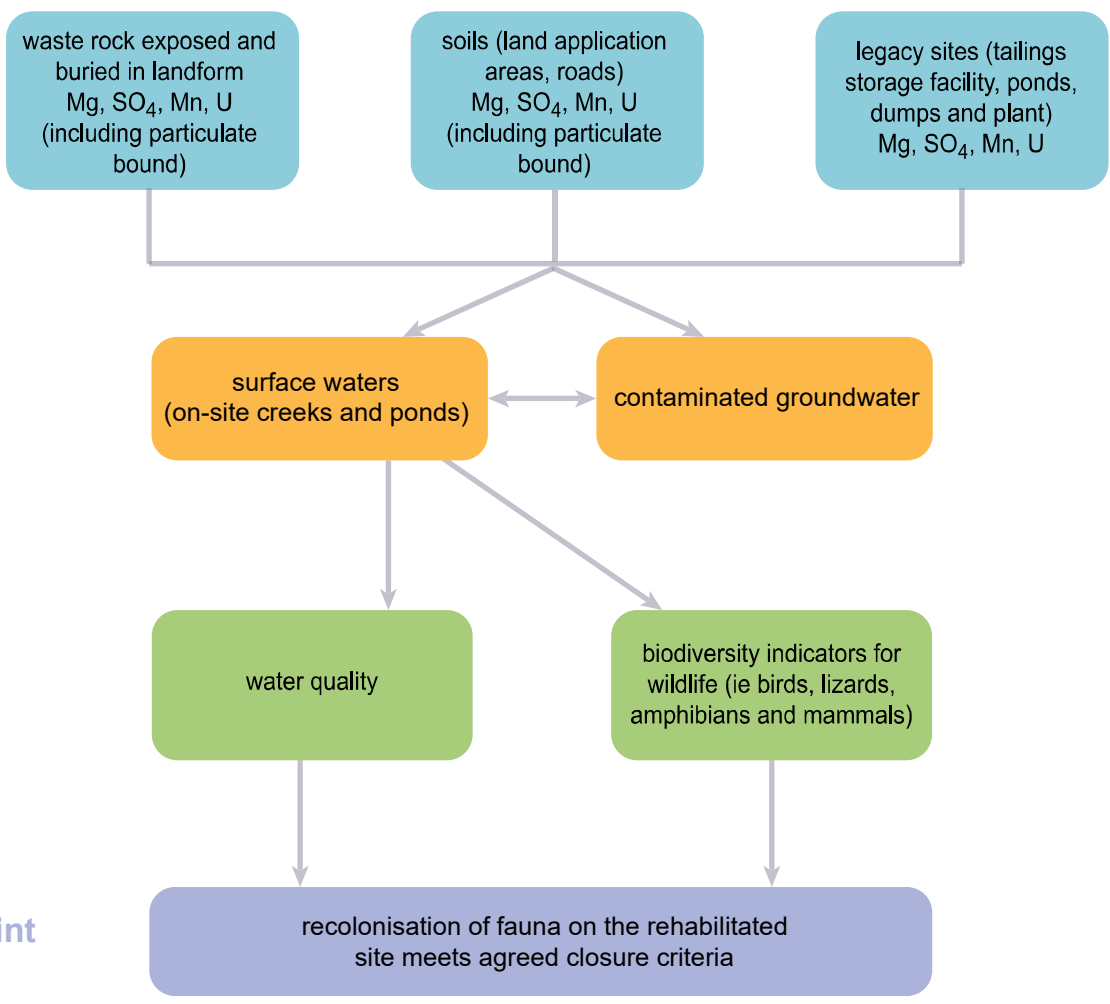

Figure 5 Example conceptual risk model used to identify knowledge needed to assess toxicity to wildlife 
By considering a consistent set of questions for each node within each level of the relevant conceptual model (i.e. source, stressor, pathway, measurement endpoint, assessment endpoint), research knowledge needs were identified. The questions related to what is known or not known about the risk, or whether there are any risks missing that need to be included. Referred to as key knowledge needs (KKNs), these were reviewed by ARRTC members and prioritised according to the magnitude of the risk, when the knowledge is required, and the time it would take to generate the knowledge.

A final list of $127 \mathrm{KKNs}$, divided into five themes (i.e. landform; water and sediment; health impacts of radiation and contaminants; ecosystem restoration; and cross-themes), were subsequently endorsed by ARRTC and published (Department of the Environment and Energy 2017). Each KKN consists of a title, one or more corresponding questions, and a description for each question (Table 1).

Table 1 Examples of key knowledge needs and associated questions to assess toxicity to wildlife

\begin{tabular}{|c|c|}
\hline Title & Question/s \\
\hline \multirow{2}{*}{$\begin{array}{l}\text { Characterising contaminant } \\
\text { sources on the mine lease }\end{array}$} & $\begin{array}{l}\text { What contaminants (including nutrients) are present on the } \\
\text { rehabilitated site (e.g. contaminated soils, sediments and } \\
\text { groundwater, tailings, and waste rock)? }\end{array}$ \\
\hline & $\begin{array}{l}\text { What factors are likely to be present that influence the mobilisation } \\
\text { of contaminants from their source/s? }\end{array}$ \\
\hline \multirow{5}{*}{$\begin{array}{l}\text { Predicting transport of } \\
\text { contaminants in surface water }\end{array}$} & $\begin{array}{l}\text { What is the nature and extent of surface water movement, now and } \\
\text { over the long-term? }\end{array}$ \\
\hline & $\begin{array}{l}\text { What factors are likely to be present that influence contaminant } \\
\text { (including nutrients) transport in the surface water pathway? }\end{array}$ \\
\hline & Where and when does groundwater discharge to surface water? \\
\hline & $\begin{array}{l}\text { What factors are likely to be present that influence contaminant } \\
\text { transport (including nutrients) between groundwater and surface } \\
\text { water? }\end{array}$ \\
\hline & $\begin{array}{l}\text { To what extent will the interaction of contaminants between } \\
\text { sediment and surface water affect their respective qualities? }\end{array}$ \\
\hline $\begin{array}{l}\text { Impacts of contaminants on } \\
\text { wildlife }\end{array}$ & $\begin{array}{l}\text { Will contaminant concentrations in surface water (including creeks, } \\
\text { billabongs, and seeps) pose a risk of chronic or acute impacts to } \\
\text { terrestrial wildlife? }\end{array}$ \\
\hline
\end{tabular}

\section{Research program development}

Following finalisation of the KKNs, responsibility for undertaking research projects to generate the required knowledge was allocated to the mine operator and/or the Supervising Scientist, according to available expertise/resources and relevant accountability within the respective organisations. Each KKN was also prioritised according to when the information is needed during the Ranger rehabilitation process, as outlined in the mine operator's closure plan (Energy Resources of Australia Ltd 2018). For example, the knowledge needed to inform the backfill of mine pits with tailings (e.g. contaminant transport in groundwater and isolation of tailings) are required several years before the knowledge needed to inform the construction of the final overall rehabilitated landform (e.g. effects of waste rock properties on establishment and sustainability of revegetation).

Individual research project/s have been allocated to each KKN and a joint project list developed by the Supervising Scientist and the mine operator for endorsement by ARRTC. This provides assurance to 
stakeholders that all projects have been adequately identified and planned, so that the information to address each KKN will be generated when it is needed to inform the rehabilitation process. The Supervising Scientist has scheduled over 60 research projects to be undertaken between 2019 and 2026 and the mining operator over 100 projects during the same period. The information outputs of each Supervising Scientist research project are provided to the mine operator in the first instance, in the format of a technical report/memo. Many of the research findings are also published as peer-reviewed scientific papers to provide assurance that the work is undertaken to the highest standard.

\section{$4 \quad$ Ongoing review}

As research projects are completed and the required knowledge is obtained, the relevant KKNs will be progressively completed. To remain relevant throughout the rehabilitation planning and execution processes, the KKNs and their associated research projects also need to be adaptable, particularly as the environmental risk profile may change over time. Regular and transparent review of the KKNs is therefore required, which may result in their amendment due to any of the following reasons:

- Addition: when a new issue emerges and associated knowledge needed to address it is not already covered by the existing KKNs (e.g. via updated risk assessment).

- Modification: improvement to wording to better clarify intent, the nature of the knowledge need has changed.

- Close-out: the knowledge needed has been acquired.

- Removal: clearly demonstrated that it is no longer necessary for informing mine operations and/or rehabilitation (e.g. an environmental risk is lowered to an acceptable level).

A formal protocol has been developed, to ensure that any proposed amendments are undertaken in a transparent and scientifically-rigorous manner. Proposed amendments can be made by either the Supervising Scientist, the mine operator, ARRTC member/s, or other key stakeholder (i.e. representatives of local traditional owners, regulatory agencies). The process requires that all stakeholders review the proposed amendments prior to their implementation.

\section{Conclusion}

A framework was established for the identification and prioritisation of the environmental research required to inform the rehabilitation of Ranger uranium mine. This was undertaken in consultation with the mine operator, key stakeholders and independent scientific experts to ensure that the most important research is completed. As research projects to generate the required knowledge are completed within required timeframes, a formal close-out protocol is being implemented to ensure that the views of all relevant stakeholders are considered. Through this process, the knowledge required to successfully rehabilitate Ranger will be systematically obtained and applied to ensure the rehabilitation objectives are achieved, and the people and the environment of Kakadu National Park are protected into the future.

\section{Acknowledgement}

We acknowledge the contribution of all stakeholders to the risk assessment and key knowledge needs development process including past and present employees of Energy Resources of Australia Ltd, Gundjeihmi Aboriginal Corporation, Northern Land Council, and ARRTC. 


\section{References}

Bartolo, R, Harford, A, \& van Dam, RA n.d., 'Rehabilitation and close-out ecological risk assessment for Ranger Uranium Mine: Risk screening and prioritization', Integrated Environmental Assessment and Management, submitted for publication.

Bartolo, R, Paulka, S, van Dam, RA, lles, S \& Harford, A 2013, Rehabilitation and closure ecological risk assessment for Ranger Uranium Mine: Documentation of initial problem formulation activities, Internal Report 624, Department of the Environment and Energy, Canberra.

Commonwealth of Australia 1978, Environment Protection (Alligator Rivers Region) Act 1978.

Commonwealth of Australia 2018, Australian and New Zealand Guidelines for Fresh and Marine Water Quality, www.waterquality.gov.au/anz-guidelines

Department of the Environment and Energy 1999, Environmental Requirements of the Commonwealth of Australia for the Operation of the Ranger Uranium Mine, Commonwealth of Australia, Canberra, http://www.environment.gov.au/science/supervisingscientist/publications/environmental-requirements-ranger-uranium-mine

Department of the Environment and Energy 2017, Alligator Rivers Region Technical Committee: Key Knowledge Needs: Uranium Mining in the Alligator Rivers Region, Supervising Scientist Report 213, Commonwealth of Australia, Canberra.

Director of National Parks 2016, Kakadu National Park Management Plan 2016-2026, Department of Environment and Energy, Commonwealth of Australia, Canberra.

Energy Resources of Australia Ltd 2018, Ranger Mine Closure Plan, Revision number 0.18.0, http://www.energyres.com.au/sustainability/closureplan/

Miller, JP 2019, 'Environmental regulatory oversight: transitioning from an operational to rehabilitation framework', in M Tibbett \& AB Fourie (eds), Proceedings of the 13th International Conference on Mine Closure, Australian Centre for Geomechanics, Perth, pp. 771-780.

Standards Australia/Standards New Zealand 2009, AS/NZS ISO 31000:2009 Risk management-principles and guidelines.

Standards Reference Group SERA 2017, National standards for the practice of ecological restoration in Australia, 2nd edn, Society for Ecological Restoration in Australia.

US Environmental Protection Agency 1998, Guidelines for Ecological Risk Assessment, EPA/630/R-95/002F, United States of America, Washington. 
